\title{
Thermal Spray Copper Alloy Coatings as Potent Biocidal and Virucidal Surfaces
}

\author{
J. Mostaghimi ${ }^{1} \cdot$ L. Pershin ${ }^{1} \cdot$ H. Salimijazi ${ }^{2} \cdot$ M. Nejad $^{3} \cdot$ M. Ringuette $^{1}$
}

Submitted: 8 October 2020/in revised form: 29 December 2020/ Accepted: 8 January 2021/Published online: 28 February 2021 (C) ASM International 2021

\begin{abstract}
Microbial and viral pathogen contamination of touch surfaces contributes to the rapid transmission of diseases. It has been known for decades that microbes and viruses are rapidly inactivated when exposed to copper and its alloys. Consequently, the use of thermal spray technologies to coat surfaces in healthcare and public settings has been receiving a considerable amount of interest during recent viral pandemics and particularly now with COVID19. This review is focused on recent successes using thermal spray technology to uniformly coat metal and organic surfaces, providing a rapid and economical means of inhibiting fomite transmission of pathogens on diverse surfaces with complex topographies. Emphasis is placed on the influence of lamella structure, porosity, and roughness of the coatings as it pertains to biocidal activity and the implications of using this knowledge to optimize the ability of copper coatings to irreversibly inactivate viral pathogens, regardless of their genomic mutation rates. Results of the long-term performance of the copper alloy coatings in real hospital settings in Canada and Peru are also presented.
\end{abstract}

Keywords copper/copper alloy coatings · antibacterial coatings - twin wire-arc spray coating - thermal spray of copper-based coatings on wood and polymer

J. Mostaghimi

mostag@mie.utoronto.ca

University of Toronto, Toronto, Canada

2 Isfahan University of Technology, Isfahan, Iran

3 Michigan State University, East Lansing, USA

\section{Introduction}

The COVID-19 pandemic has underscored the dire consequences of surface contamination in the transmission of microbial and viral pathogens. Fomite transmission in healthcare facilities is a major source of healthcare-acquired infections (HAI) affecting hundreds of millions of people worldwide. It impacts between 5 and $10 \%$ of acute care admissions in industrialized countries. In developing countries, the risk is two to twenty times higher and the proportion of infected patients frequently exceeds $25 \%$. A growing awareness of this problem prompted the World Health Organization to promote the creation of the World Alliance for Patient Safety (Ref 1). There is therefore considerable interest in taking advantage of metals, such as copper, whose ions can inactivate microbes and viruses within minutes on frequently touched surfaces in hospitals and public settings.

The use of copper dates back to 2600 B.C., where ancient medical texts recorded its use for sterilizing wounds and drinking water (Ref 2-5). In more recent times, for example, during the nineteenth-century cholera epidemic, Parisian physicians observed that copper workers were less prone to cholera. Historically, other physicians throughout Europe had used copper as a treatment for multiple microbial infections and inflammatory diseases such as arthritis. Numerous studies have since demonstrated that copper has more potent activity than other metals, such as silver and zinc, for destroying both microbial and viral pathogens. Thus, copper represents a nontoxic, cost-effective, and eco-friendly way of countering the spread of pathogens (Ref 6,7). The US Environmental Protection Agency (EPA) has acknowledged the antimicrobial efficacy of over 500 copper-based alloys with an average biocidal rate of approximately $99 \%$ within 2 
hours of contact for alloys containing $60 \%$ or higher concentrations of copper ( $\operatorname{Ref} 2,5-8)$.

Our mechanistic understanding of the diverse oligodynamic activities of copper on microbial organisms has greatly expanded over the last decades. Copper, mainly oxidized $\mathrm{Cu}^{2}$ ions in biological systems, serves as essential co-factors for a broad spectrum of enzymatic activities which are critical for microbial reproduction, survival, and functions. It is estimated that $0.3 \%$ of bacterial proteomes are cuproproteins (Ref 9). Complex metal efflux systems exist to protect microbes from building up to toxic levels of metal ions. However, despite the presence of these efficient detoxification systems, at concentrations that are well below levels harmful to humans, excess copper is toxic to microbes. Inactivation mechanisms appear to involve a complex combination of factors. Copper has a high affinity for functional groups of proteins, such as carbohydrates, thiol, and amino groups. Thus, the presence of excess copper can have multiple negative structure-function consequences. Copper ions can also compete with other essential metals such as magnesium, manganese, iron, and zinc for their binding sites. The combination of aberrant binding to functional groups and metal substitution activities can thus lead to the disruption of a wide variety of metabolic and biosynthetic pathways.

Oxygen freely diffuses across plasma membranes, which can be converted into a mixture of superoxides and hydrogen peroxide. In bacteria, aerobic metabolism is the main source of hydroxide radicals and hydrogen peroxide. These reactive metabolic by-products are generally not toxic because of the protection provided by superoxide dismutase, catalases, and molecular scavengers to protect microbes [10]. However, in the presence of excess metal ions, such as copper, the normal checks and balance to oxidative stress are overwhelmed. Copper via a combination of Fenton-like and Harber-Weiss reactions can convert the superoxide anions and hydrogen peroxide into highly reactive hydroxyl radicals.

$$
\begin{array}{r}
\mathrm{Cu}^{2+}+\mathrm{O}_{2}^{-} \rightarrow \mathrm{Cu}^{+}+\mathrm{O}_{2} \\
\mathrm{Cu}^{+}+\mathrm{H}_{2} \mathrm{O}_{2} \rightarrow \mathrm{Cu}^{2+}+\mathrm{HO}+\mathrm{HO}^{-} \text {Fenton - like } \\
\mathrm{O}_{2}^{-}+\mathrm{H}_{2} \mathrm{O}_{2} \rightarrow \mathrm{O}_{2}+\mathrm{OH}^{-}+\mathrm{OH} \quad \text { Harber - Weisss }
\end{array}
$$

The resultant oxidative stress can have a series of destructive impacts on the biomolecules they target. For some bacteria, plasma membrane lipid peroxidation resulting from exposure to copper appears to be the primary cause of cell death. The resultant loss of plasma membrane integrity results in the leaking of intracellular components and loss of osmotic balance. The free radical can also cause extensive damage to nucleic acids, proteins, and carbohydrates, over time further compromising survival (Ref 11).
Exposure of Bacillus globigii endospores to modified Fenton formulations containing cupric chloride, ascorbic acid, and $\mathrm{NaCl}$ under aerobic conditions results within 30 minutes up to a 6-order-of-magnitude inactivation of the endospores. A model was proposed whereby copper ions diffuse into the spores, converting dissolved $\mathrm{O}_{2}$ into toxic hydroxyl radicals (Ref 12). We observed under normal atmospheric conditions that exposure of Bacillus subtilis endospores to copper surfaces leads to the destruction of endospore morphology and inactivation within a couple of hours (Ref 41). In light of the above, it is conceivable that surface copper ions diffused into the spores to convert dissolved $\mathrm{O}_{2}$ into hydroxyl free radicals, albeit at a slower rate than with the presence of Fenton formulations. The possibility cannot be eliminated that hydroxyl radicals generated on the exterior of the endospores also contributed to the destruction of endospore coats. Surfaces with a copper content greater than $70 \%$ also resulted in a significant inactivation of Clostridium difficile vegetative cells and spores compared with stainless steel (Ref 13), indicating that metabolically inactive spores are sensitive to the toxic effects of copper ions.

For nonenveloped, single-stranded RNA viruses like norovirus, it appears that Fenton-like reactions are not primarily responsible for their inactivation on dry copper surfaces; quenching of superoxide and hydroxyl radical has no significant impact on inactivation. Instead, $\mathrm{Cu}$ (II) ions, and particularly $\mathrm{Cu}(\mathrm{I})$ ions, direct association with their RNA genomes appear to be the underlying cause (Ref 14). Intimate contact of copper ions with genomes also appears to play an important role in the inactivation of DNA viruses. However, the precise mechanism of genome inactivation is likely to be multifactorial as genomes are in intimate contact with structural and regulatory proteins (Ref 15-17).

Copper and copper alloys have proven to be effective at inactivating COVID-19/ SARS-CoV-2 (Ref 18). The envelope of COVID-19 contains lipids, as well as proteins, and the composition of the aerosol particles released by infected individuals contains a complex mixture of compounds. Thus, it is likely that copper-mediated inactivation will likely involve Fenton-like and other chemical reactions.

Respiratory viruses are the most recurrent cause of human disease. Coronaviruses, hosted in mammalian species that jump to humans, represent the underlying cause of severe infections such as severe acute respiratory syndrome (SARS). Doremalen et al. (Ref 19) evaluated the longevity of aerosol-derived SARS-CoV-2 (henceforth referred to as COVID-19) and SARS-CoV-1 on surfaces such as stainless steel, plastic, cardboard, and copper. The aerosols $(<5 \mu \mathrm{m}$ drop size) had viral titers similar to those observed in samples obtained from the upper and lower respiratory 
tract in humans. They found that viable COVID-19 particles were detectable on stainless steel and plastic surfaces up to $72 \mathrm{~h}$, and the stability of SARS-CoV-1 was similar on these surfaces. In contrast, on copper, no viable COVID-19 particles were detected after 4 hours and for SARS-CoV-1 after 8 hours.

Similarly, S. Warnes et al. (Ref 20) studied pathogenic human coronavirus HuCoV-229E viability on different surfaces. The authors reported that the coronavirus $229 \mathrm{E}$ remained infectious in a human lung cell culture for at least 5 days (at $21^{\circ} \mathrm{C}$ and relative humidity of $30 \%$ to $40 \%$ ) on common nonbiocidal surfaces including polymers, such as Teflon and PVC, ceramic tiles, glass, and stainless steel. However, the HuCoV-229E was inactivated on copper alloys in less than $60 \mathrm{~min}$. CuZn alloys were found to be particularly effective at inactivating $\mathrm{HuCoV}-229 \mathrm{E}$, with efficacy being directly proportional to the percentage of copper. Copper-nickel alloys were also effective but required $90 \% \mathrm{Cu}$ content to match the inactivation degree of the brasses containing $70 \% \mathrm{Cu}$.

Several studies examined the effects of various antimicrobial coatings (Ref 21-23, 24, 25). For example, Appeartex ${ }^{\circledR}$ (Appeartex AB, Sweden) is a composite material composed of biocidal polyhexamethylene biguanide and a hydroscopic surfactant that traps negatively charged microbes. Even if the biocidal agent is washed off during cleaning, the positive surface charge of the surfactant inhibits the release of bacteria from the contaminated surface. However, a copper surface was significantly more effective in lowering the colony-forming units (CFU) than Appeartex ${ }^{\circledR}, 42 \%$ reduction rate over a period of 10 weeks. Hedin et al. investigated the use of Appeartex ${ }^{\circledR}$ on lowlevel contamination on bedside tables, while Casey et al. assessed contamination of copper surfaces on door handles and taps (Ref 21,23) The surfaces found to have greatest bacterial counts are the bedrail, light switches, door handles, bedside tables, over-bed tables, intravenous pumps, and chairs (Table 1), which account for $40 \%$ to $49 \%$ of hospital contact (Ref 32-39).

The use of copper alloys in hospital wards would significantly decrease bacterial contamination compared to stainless steel, wood, or polymer surfaces. Copper-coated, frequently touched hospital surfaces were shown to reduce bacterial loads by 90 to $100 \%$ three months after implementation (Ref 3). However, the high cost of copper makes it not a commercially viable option for manufacturing hospital furniture. There are also major manufacturing challenges in the cladding of complex surfaces with copper sheet metal. An appealing alternative is the application of a very thin metal coating on surfaces using a thermal spray technology that enables the economical deposition of thin, dense metal coatings on various and complex substrates $[26,27]$.

\section{Thermal Spray Coatings Have Potent Biocidal Properties}

The twin-wire-arc spray process (TWA) is well suited for the deposition of copper coatings in comparison with atmospheric plasma spraying (APS) or other thermal spray processes. The process advantages include a much higher deposition rate, about 3-4 times higher than for APS for example when depositing NiAl coating (Ref 28). Additionally, TWA operates at much lower power levels between 2 and $10 \mathrm{~kW}$. Thus, the lower arc power and its small volume result in low gas temperatures and substrates heating which enables coatings deposition on low-meltingpoint substrates such as polymers. For TWA unlike for APS, all sprayed particles are in a molten state. The equipment for TWA is one of the simplest with a low initial cost, and wires as a feedstock material also have a great cost advantage in comparison with powders, which makes the process very cost-effective. For example, selecting TWA instead of the APS process for deposition of NiAl coatings for jet engines overhaul allowed to improve the coating adhesion, machinability, and cost savings $\sim 55 \%$ per part (Ref 29). Several developments in wire-arc spraying open possibilities for applications in high added value processes such as the coatings of aluminum engine blocks in the automotive industry or spray forming of molds for rapid tooling (Ref 30, 31).

Sharifahmadian et al. (Ref 26) studied copper coatings' antibacterial properties deposited by TWA spraying. Figure 1 shows the micrograph of the bulk copper metal and the copper coating structure, illustrating the lamellar structure Fig. 1(b). The lamellas' boundaries are enriched with copper oxide, micropores, and microcracks. They reported that Gram-negative Escherichia coli was more sensitive to the inhibitory action of the copper coating (97\% after 6 h), whereas for Gram-positive Staphylococcus aureus bacteria the reduction was $92 \%$ after $6 \mathrm{~h}$.

In comparison with the bulk copper which has large grains, the copper coating with a much finer grain structure was almost twice effective and faster (Fig. 2). The relationships between surface properties, such as the surface free energy, and its antibacterial behavior were studied (Ref 40, 41). The authors determined that the surface characteristics of the as-deposited copper coatings, such as the higher roughness, surface free energy, the finer grain structure, are important factors affecting the antibacterial behavior of the coatings (Fig. 3). Defects such as incoherent twin boundaries, micropores, and microcracks are energetically favorable as segregation points for solute atoms such as oxygen. These sites contribute to differences in energy states on the copper coating and, hence, provide the necessary driving force for sustained dissolution of 
Table 1 Surfaces with the greatest mean total bacterial counts

\begin{tabular}{lccc}
\hline \multicolumn{1}{c}{ Surface } & $\begin{array}{c}\text { Range of bacterial counts } \\
\text { CFU/25, cm }\end{array}$ & Mean total bacterial counts CFU/25, $\mathrm{cm}^{2}$ & Number of articles \\
\hline Bedrail & $3-6162.8$ & 1473 & 3 \\
Light switch & $75-1395$ & 735.0 & 2 \\
Door handle & $15-4375$ & 727.2 & 3 \\
Bedside table & $0.96-3689.9$ & 579.1 & 3 \\
Chair & $0.3-2385$ & 358 & 3 \\
\hline
\end{tabular}

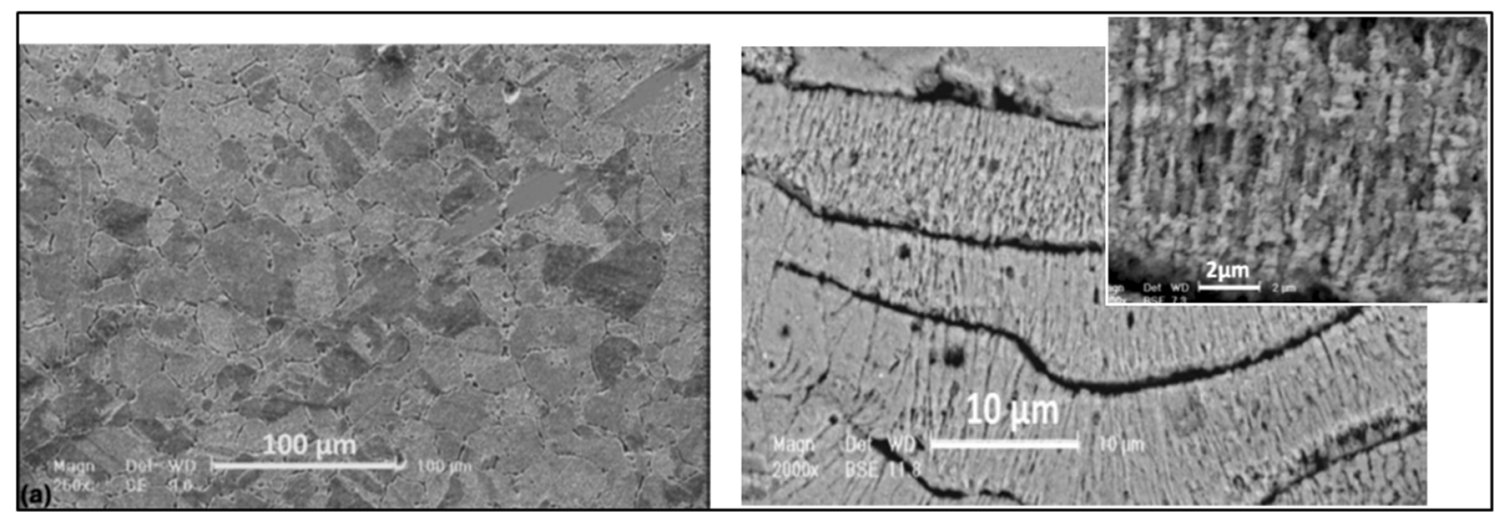

Figure 1 Microstructure of a bulk copper (left) and a wire-arc-sprayed copper coating (right) with orientation of grains in a lamella (insert) [20]

metal ions from the surface. The copper nanocrystals, and their association with $\mathrm{Cu}-\mathrm{O}$ super-oxides acting as preferential dissolution sites in aqueous media, are crucial to providing enhanced antibacterial activity. The largest bacteria reduction was found for $E$. coli and $S$. aureus at $96 \%$ and $92 \%$, respectively, on the as-sprayed copper coating, while it was $65 \%$ and $59 \%$ correspondingly for the solid copper surface (Ref 40).

Nanostructured titania and conventional fused-and-crushed $\mathrm{TiO}_{2}$ powders were mixed with copper powder (5 wt.\%) before deposition (Ref 43). The flame spray coatings were polished after deposition to an average roughness of $\mathrm{Ra} \sim 1 \mu \mathrm{m}$ to simplify bacteria release for following bacteria colonies counting to evaluate the coating efficacy. Adding a small amount of copper to $\mathrm{TiO}_{2}$ and irradiating the coating with white light significantly enhanced bactericidal efficacy. This was attributed to the production of reactive oxide species, such as the hydroxide ions, that damaged the cells. However, the copper-free $\mathrm{TiO}_{2}$ coatings have no significant biocidal activity due to the phase transformation from the metastable anatase phase of the original stock power being converted to $100 \%$ rutile phase in the final coatings, while the $\mathrm{TiO}_{2}-\mathrm{Cu}$ coating shows approximately 9 vol. $\%$ anatase. The authors suggested that the presence of the anatase was due to the cooling effect of copper powder when part of the flame energy was transferred to the melting of the copper.

In work by Sanpo et al. (Ref 44) the authors studied the biocidal effect of copper addition to a composite powder. They used for cold spraying a mixture of aluminum-based chitosan-copper composite powders with various ratios of Al to $\mathrm{CS}-\mathrm{Cu}$ powders. Chitosan, a natural polymer, has attracted considerable attention due to its beneficial biological activities, such as biodegradability and biocompatibility in coatings for implants, and adding antibacterial copper could reduce rejection rate. The results showed that all cold-sprayed samples had a higher killing rate of $E$. coli in comparison with the initial powders, and the killing rate increases with increasing $\mathrm{CS}-\mathrm{Cu}$ powder concentration in the powder composition.

A. Wrona et al. (Ref 45) studied the biocidal activity of APS coatings deposited from pure copper, CuNi35, and CuSn10 alloys. The coupons had various surface roughness: from as-sprayed $(\mathrm{Ra}=2,5 \div 4.32 \mu \mathrm{m})$ to highly polished $(\mathrm{Ra}=0.19 \div 0.04 \mu \mathrm{m})$. Three bacteria strains were used $S$. aureus ATCC 25923, E. coli ATCC 25922, and P. aeruginosa ATCC 9027.

The largest reduction for S. aureus ( $95 \%$ ) was observed on as-sprayed CuSn10 coating after 24-h inoculation. In contrast, the as-sprayed $\mathrm{CuNi} 35$ coating with the lowest 
Figure 2 Reduction in bacterial numbers after contact with different surfaces (a) S. aureus NCTC 11047, (b) E. coli NCTC 10418 [20]
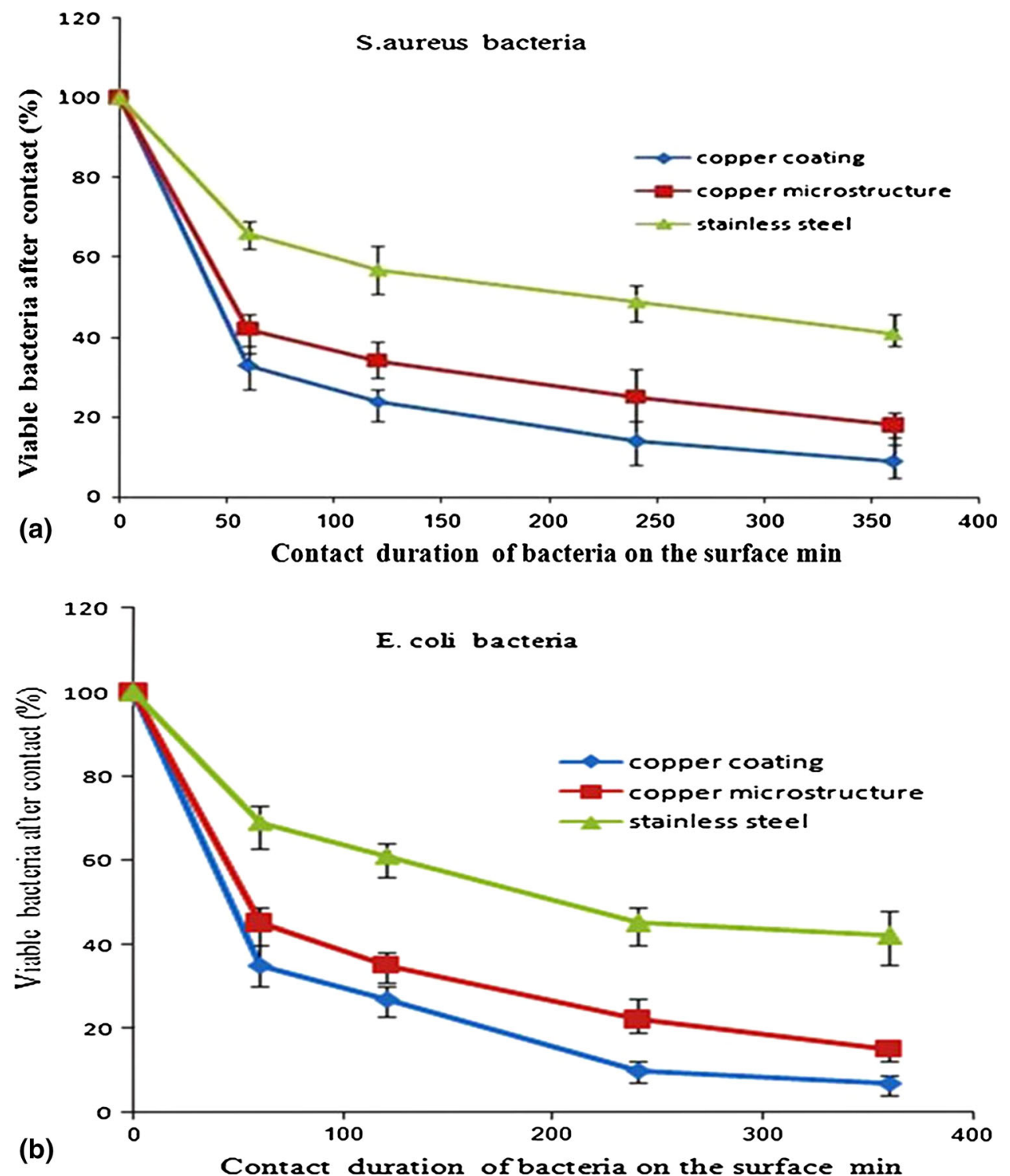

Figure 3 SEM micrographs of the as-sprayed copper coating surface

copper content showed an increase in bacterial colonies in relation to the control (stainless steel).
For the $E$. coli above $70 \%$ reduction of bacteria, the load was noted after $2 \mathrm{~h}$ for all the types of coating. However, 
for the $\mathrm{Cu}$ and $\mathrm{CuNi} 35$ coatings, after $24 \mathrm{~h}$ significantly lower reduction or even increase in CFU in relation to the control was observed. The reason for low biological activity had been attributed to differences in composition between cell membranes in methicillin-susceptible (MSSA) and methicillin-resistant (MRSA) strains. This can result in distinct susceptibility to antimicrobial agents and sanitizers and hence activity toward copper surfaces. For $P$. aeruginosa after $2 \mathrm{~h}$, reduction of bacteria colonies to $90 \%$ and after $24 \mathrm{~h}, 100 \%$ was reported. The authors had concluded that there was no clear relationship between surface roughness and biological activity in their studies (Ref 45).

Pure copper coating deposited by APS had a weaker antimicrobial effect on $S$. aureus than TWA coatings as reported by Sharifahmadian et al. (Ref 26). Better antimicrobial properties of the TWA-sprayed copper coating could be due to the higher oxide content, pores, microcracks, and defects compared to the APS coating. For all the coatings with the polished surface, a noticeable reduction in bacteria was observed after $2 \mathrm{~h}$. In the case of E. coli reduction was more than $70 \%$ in comparison with the control. For the $P$. aeruginosa strain, bacteria reduction was about $90 \%$. After $24 \mathrm{~h}$, for all the coatings, an increase in biocidal efficacy and a degree of reduction of $P$. aeruginosa up to $100 \%$ were reported.

D. Tejero-Martin et al. (Ref 46) exploited the benefits of the addition of silver nanoparticles as a biocidal agent into hydroxyapatite or chitosan polymer in the prevention of infections for implants. These functional materials were deposited by flame and cold spraying. For applications in healthcare facilities, K. J. Brobbey et al. (Ref 47) developed a novel high-speed production of antibacterial fabrics. They used liquid precursor flame spray pyrolysis to deposit silver nanoparticles on two commonly used fabrics in hospitals. To improve the nanoparticle fixation and provide the surface hydrophobicity some samples were then coated by polymer coating (hexamethyldisiloxane) in an RF plasma chamber. They performed a newly developed touch test to measure the antibacterial properties of the coated fabrics against $E$. coli and $S$ aureus. The average surface coverage of the fabrics with spherical nanosilver particles was around $40 \%$. The average particle size was around 32 $\mathrm{nm}$, and the amount of silver particles on the surface of the fabrics was $5 \mathrm{wt} \%$ and $9 \mathrm{wt} \%$. The polymer coating thickness was around 50 and $90 \mathrm{~nm}$. Figure 4 shows the SEM micrographs of the two coated fabrics with silver nanoparticles. The growth of E. coli was inhibited in all the samples that had deposited silver nanoparticles. For Grampositive $S$. aureus, the silver coatings did not demonstrate antibacterial properties even for a higher load of silver. The authors concluded that higher amounts of silver are needed to create significant antibacterial properties against $S$. Aureus.

\section{Effect of Surface Roughness on Bacterial Adhesion}

The surface topography can affect bacteria attachment, and this strongly depends on the roughness scale. Previously published studies have shown that the micro-roughness can influence the attachment of cells. It was demonstrated that the cells grew along the grooves in long rows or the cells tended to be attached to the grain boundaries (Ref 48, 49, 52). Some studies, however, have reported that bacteria have no preference for adhesion to surface scratches or grooves and roughness plays a minor role in the attachment mechanism (Ref 50, 51, 53).

Shafaghi et al. (Ref 41) studied the effect of surface roughness on bacteria killing for the wire-arc deposited copper alloy coating (CuNi17Zn16) and the sheet metal substrate of the same composition. The coating and the sheet metal samples were polished to achieve two levels of roughness with Ra 0.1 and $3.5 \mu \mathrm{m}$. The latter was selected based on "positive feeling" which is associated with touching surfaces with roughness values of between $\mathrm{Ra} 2$ and $4 \mu \mathrm{m}$ (Ref 54). The authors demonstrated that the presence of the grooves results in a great accumulation of bacteria around the surface asperities (Fig. 5).

Despite a 35-fold difference in Ra values, copper alloy sheet and copper coatings were equally effective in killing Gram-negative, E. coli, and Gram-positive, S. epidermidis. Greater than $95 \%$ of the bacteria were killed within 5 minutes with no significant difference between solid metal and sprayed coating as well as for smooth or rougher surface finish (Fig. 6).

\section{Spores on Copper Coatings}

A subset of environmentally stressed bacteria typically forms resilient dormant spores as part of a survival strategy. These spores can remain viable for years and are resistant to heat desiccation, and bactericidal drugs. The spores are problematic in healthcare and food preparation industries owing to their ability to germinate in favorable conditions, giving rise to high concentrations of pathogenic bacteria. Shafaghi et al. (Ref 41) demonstrated that the copper alloy coating and sheet metal were very effective in the killing of spores of $B$. subtilis bacteria in just two hours of exposure (Fig. 7). The endospores that were exposed to the copper alloy formed petal-like nanostructures after 2 hours of exposure. By the $7^{\text {th }}$ day, almost all the endospores were degraded and transformed into nanostructures (Fig. 8). Employing SEM with focused ion beam (FIB), Shafaghi et al. analyzed these structures and proposed that the proteins derived during spore degradation served as the nucleation sites that formed copper phosphate crystals.

The formation of nanoflowers can be indicative of the spores' killing efficiency. The mechanism by which 

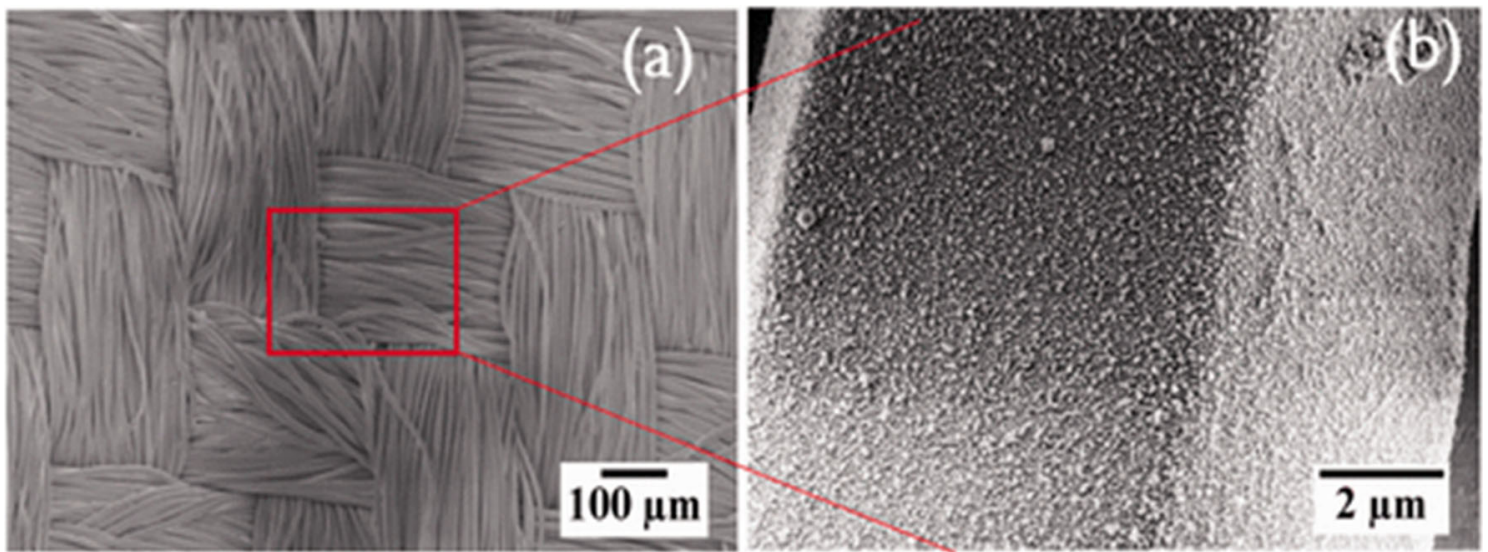

Figure 4 Silver nanoparticles deposited onto the fabric fibers [32].

Figure 5 SEM images of bacteria on copper alloy coating. (a) Surface (Ra $3.5 \mu \mathrm{m}$ ) with random orientation of bacteria in scratches,

(b) bacteria deformation due to stress induced by exposure to copper [28].
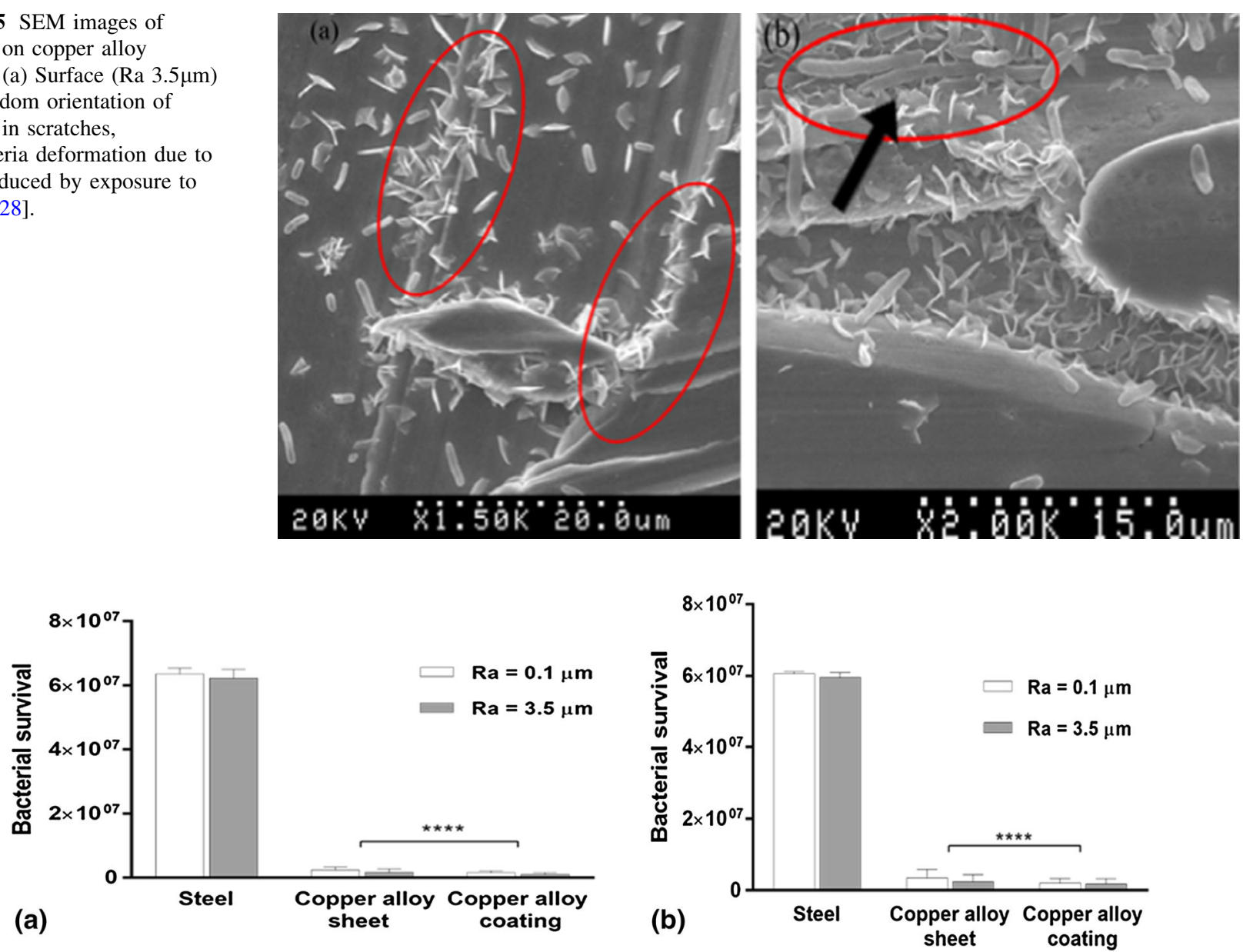

Figure 6 Bacterial survival (a) E. coli and (b) S. epidermidis on copper alloy surfaces in comparison with stainless steel

exposure to copper results in spore degradation is not entirely understood. It is possible that the copper ions bind with the negatively charged spore coat proteins. These bound copper ions interact with dissolved oxygen and can then generate hydrogen peroxide and other reactive oxygen species that could trigger the destruction of the protective spore coat and internal structures. 


\section{Biocidal Activity of Copper Coatings in a Hospital Setting.}

Our work at Toronto General Hospital has demonstrated the effectiveness of copper alloy coatings in significantly reducing bacterial loads on the arms of chairs in an emergency room waiting/visiting area up to 1 year after coating and installation (Fig. 9). For this study, seventy-six chairs were placed in the waiting room area of the hospital, thirty-eight chairs had arms with a thermally sprayed

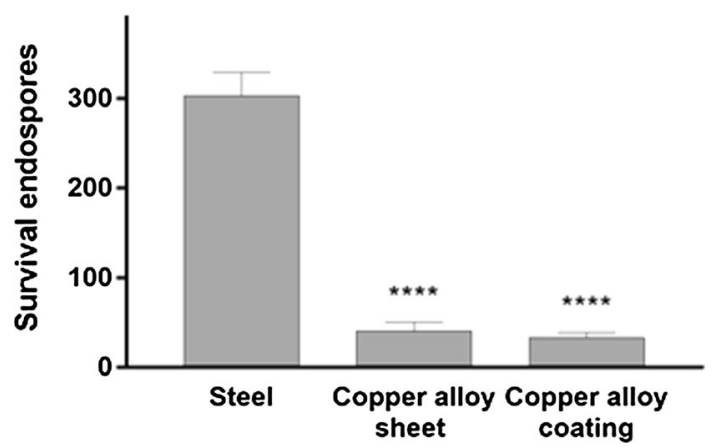

Figure 7 Comparisons of $B$. subtilis endospore survival of stainless steel, copper alloy sheet, and thermal spray copper alloy on surfaces with roughness $\mathrm{Ra}=3.5 \mu \mathrm{m}[28]$ copper alloy coating, and the remaining chairs (controls) had standard polymer armrests.

A twin-wire-arc spray unit ValuArc with high-velocity cup (Oerlikon Metco, Westbury, NY, US) was used for coating deposition under operating parameters: arc current $280 \mathrm{~A}$, voltage $28 \mathrm{~V}$. The wires were made from C75200 copper alloy (CuNi18Zn13), which is registered as antimicrobial by Environmental Protection Agency. Additionally, the copper-nickel alloys have good corrosion resistance and are extensively used in seawater and saline environments in desalinization plants (Ref 42). The coatings average thickness was $300 \mu \mathrm{m}$, and its surface was finished by an emery paper to roughness $\mathrm{Ra} \sim 0.5 \mu \mathrm{m}$.

Periodic surface sampling was done until 264 days after installation. Housekeeping procedures were not altered for the study. On each sampling day, 16 copper alloy-coated chairs and 16 controls were randomly selected; then, a plastic template and flocked swab was used to swab on one arm of each chair.

Overall, copper alloy-coated arms showed a 64\% reduction in median aerobic $\mathrm{CFU} / \mathrm{cm}^{2}$ (1.12 versus 3.11 $\mathrm{CFU} / \mathrm{cm}^{2}$ ). Also, $78 \%$ of copper alloy-coated arms yielded less than $2.5 \mathrm{CFU} / \mathrm{cm}^{2}$, which is the suggested standard for surface cleanliness (Ref 8, 37), compared to $44 \%$ for uncoated chairs. On visual inspection, the coating showed no wear or tarnishing, and reductions in median $\mathrm{CFU} / \mathrm{cm}^{2}$
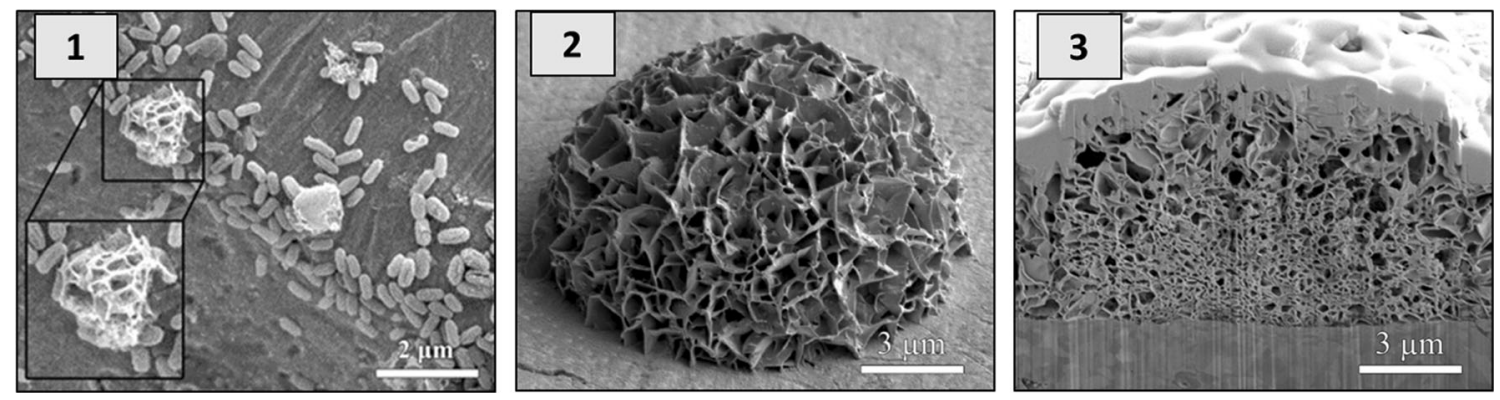

Figure 8 B. subtilis endospores degradation and transformation into nanoflowers (1), a formed nanoflower after 7 days of exposure (2), inner structure of the nanoflower (FIB cross section) (3) [28]
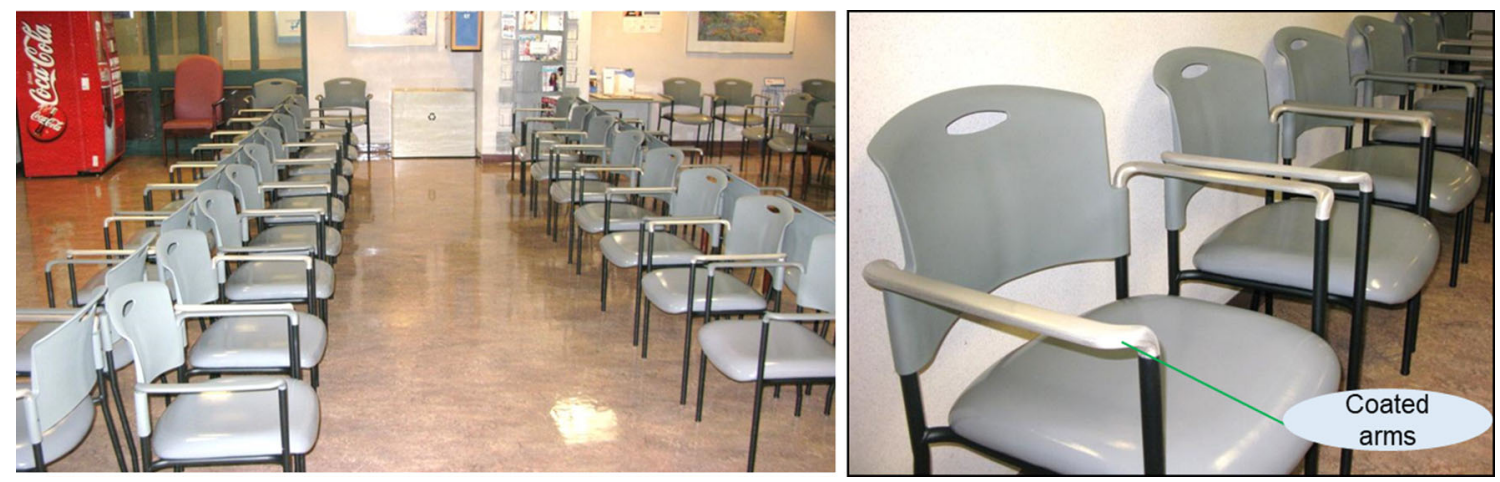

Figure 9 The waiting room and coated armchairs in Toronto General Hospital (Canada) 
did not decrease over time. The coating deposited using CuNiZn alloy had better corrosion resistance and a "clean" stainless steel appearance compared to other copper alloys; this is why they do not tarnish after touching or cleaning by the cleaning agents commonly used in hospitals.

\section{Tests in Mount Sinai Hospital (Toronto, Canada)}

As a follow-up to the above study, we evaluated the longterm effectiveness of copper alloy coatings in reducing bacterial loads on different frequently touched hospital surfaces at Mount Sinai Hospital in Toronto. For these tests, the same copper alloy-coated chairs were employed in 6 intensive care units, and samples were taken for over 2.5 years after the coating had been deposited. Additionally, various hardware in the intensive care units (ICUs), such as cabinet handles and push plates/handles for 10 doors, were coated with the same copper alloy (Fig. 10). The surfaces were sampled weekly, and the same number of uncoated and copper-coated surfaces were swabbed using a template. Copper coatings on the arms of the chairs, charting tables, and push plates resulted in a reduction of surface bacterial load by $60 \%, 42 \%$, and $23 \%$, respectively. The results suggest that the implementation of copper coating in a hospital setting is beneficial, and to reduce the bacterial load in the long term, it should be targeted to highly touched surfaces.

It is known that environmental bacterial load greater than $2.5 \mathrm{CFUs} / \mathrm{cm}^{2}$ poses a risk of infection to patients (Ref 32) no matter what type of bacteria. It was therefore encouraging to observe that only 5 of the 210 surfaces (i.e.,
$2.38 \%$ ) surfaces swabbed yielded bacterial loads greater than the standard for surface cleanliness. These 5 surfaces with higher bacterial loads were 3 control chairs without coating and 2 copper-coated cupboard handles. The location of the handles could account for this result as the cupboard handles were situated in the nursing stations, whereas the visitor chairs, charting tables, and push plates were located within the intensive care units with more stringent cleaning. Furthermore, the cupboard handles are likely to be the most frequently touched out of all studied surfaces.

\section{Tests at Instituto de Medicina Tropical Alexander von Humboldt (Lima, Peru)}

Preliminary comparison tests were conducted using pure copper sheet metal and copper alloy (CuNiZn)-coated aluminum samples. The surfaces were inoculated by 4 pathogenic bacteria: Escherichia coli, Staphylococcus aureus, Klebsiella pneumonia, and Pseudomonas aeruginosa. After spreading the bacteria on each of the surfaces, they were sampled every 15 minutes up to one hour. The pure copper and copper-coated surfaces had a similar bactericidal effect: the Gram-negative bacteria did not survive after 15 minutes, while Gram-positive $S$. aureus lasted up to 45 minutes but in much-reduced numbers.

For tests in the hospital environment four CuNiZn alloycoated aluminum plates $(100 \times 400 \times 2 \mathrm{~mm})$ were installed on the highly touched surfaces, namely on the telephone shelf in the nursing station, on the laboratory samples receiving shelf, outpatient reception shelf (Fig. 10), and on
Figure 10 Plates coated by CuNiZn alloy installed in a hospital nursing station (1), and samples receiving shelf (2) (Lima, Peru) and (3) coated doors hardware for installation in Mount Sinai Hospital (Toronto, Canada)

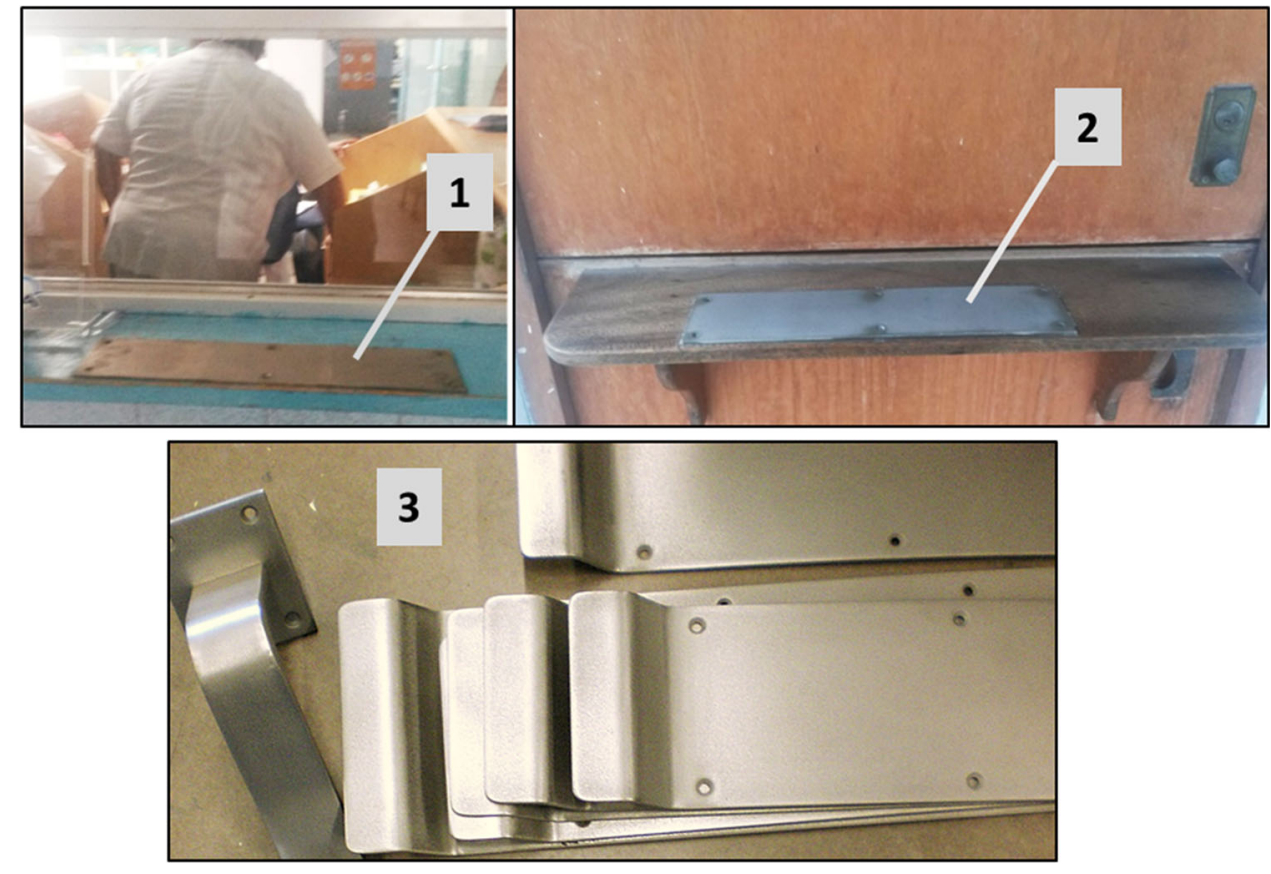


a computer desk. Sterile swabs and sterile screw-capped test tubes were used for swabbing. Each sampling area was divided into 3 sections, each one with an area of $120 \mathrm{~cm}^{2}$. After the inoculation, CFU counting was used to quantify bacterial cells that survived on the coatings. Swabbing and the colony count were performed on these surfaces during four weeks of monitoring. For all cases, the painted wood surface was swabbed before the installation of the coated plate and used as a control for the tests. The CFU counts during four weeks of monitoring are presented in Fig. 11.

The team at the Instituto de Medicina Tropical also found and identified several types of apparently copperresistant Gram-positive bacteria that may have formed biofilms. The final identification was done by DNA sequencing. These results are presented in Table 2.

\section{Coatings Evaluation After Service}

Visual examination of the coated items at Mount Sinai Hospital has shown that all coatings were in good condition one year after installation. There were no signs of visible wear or corrosion. However, on push plates and door handles the color of the CuNiZn coating was slightly darker as it was oxidized due to many contacts with the cleaning agents and hands.

In contrast, the coated plates in Lima's hospital did not perform as well. It was observed that after 14 months after installation, the coatings started to blister and peel off from the substrates.

After examination of these samples cross sections under an SEM (T-3000, Hitachi) and the composition identification by an energy-dispersive spectroscopy (EDS) unit (Quantax 70, Bruker Nano $\mathrm{GmbH}$ ) it was found that a large section of the coating was delaminated and a third dark phase was present at the coating interface. The EDS analysis allowed us to identify the dark phase as an oxygen-rich layer of aluminum oxide which had formed at the interface (Fig. 12). This could be the result of exposure of the coating to tropical environment and cleaning liquids which created conditions for copper and aluminum to form a galvanic cell. In this galvanic pair, aluminum acted as a sacrificial anode for the coating which accelerated the substrate corrosion and eventually delaminated the coating. Thus, to ensure sufficient service life of the coated parts, the service conditions and the substrate material selection should be an important consideration for future applications.

\section{Performance of Wood and Wood Products Coated by Copper}

Wood and its products are very important substrates in the application of copper-based coatings. The good performance of these coatings on wooden substrates makes this coating technology much more applicable for hospital furniture manufacturing. Wood is a biological material and susceptible to deterioration when exposed to decay fungi and insects (i.e., termites and carpenter ants) specifically for outdoor structures. (Ref 55, 56). Except for some naturally durable wood species such as cedar and redwood, most softwoods should be treated with a preservative solution to increase their service life. Copper-based preservatives are the most commonly used preservatives in the North American market. The two main copper-based preservatives are alkaline copper quaternary which contains $67 \% \mathrm{CuO}$, and copper azole that contains $96 \% \mathrm{CuO}$ (Ref 40). In addition to these preservative solutions, they are also applied to wood as suspensions of micron size (1$25 \mu \mathrm{m})$ copper particles. To ensure proper impregnation, a vacuum chamber is used to increase the penetration of these waterborne preservatives into the wood ( Ref 57, 58). The Cu-based preservative leaches heavily during the first few months, which is extremely toxic to aquatic plants and organisms even at low concentrations (Ref 59, 60).
Figure $11 \mathrm{CFU}$ counts during four weeks at different locations in the hospital (Lima, Peru)

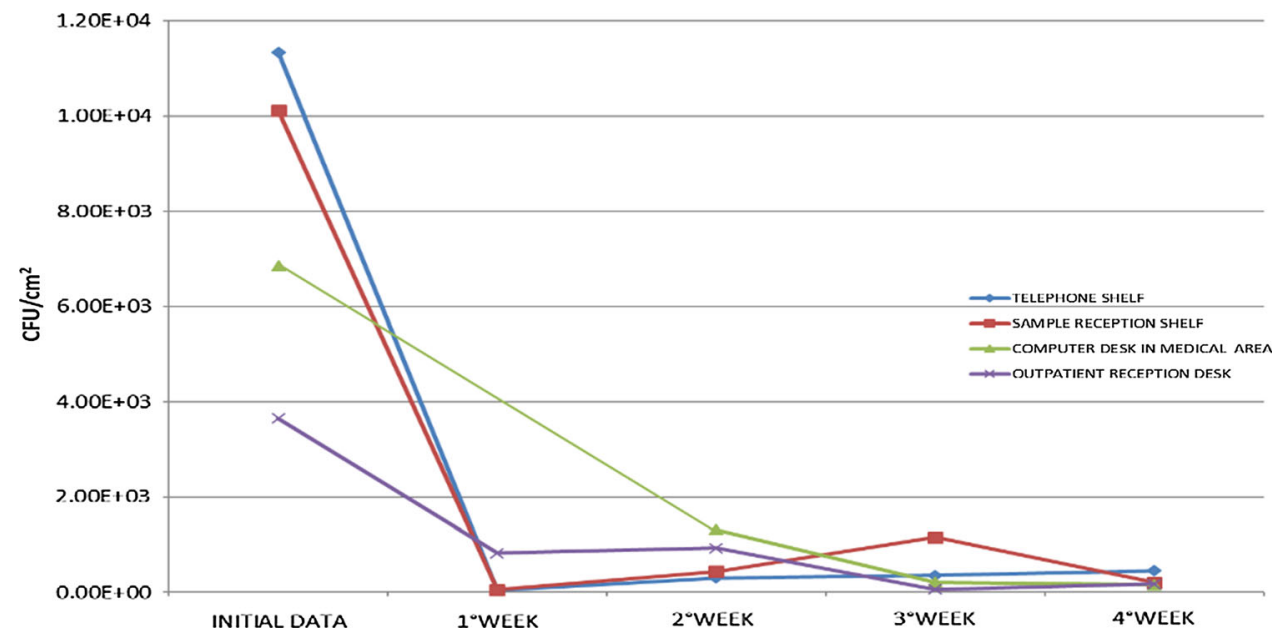


Table 2 Colonies identification and frequency results

\begin{tabular}{lc}
\hline Observed copper-resistant bacterial phenotypes, identified by whole-genome sequencing & $\%$ out of all colonies \\
\hline Mucous, translucent colonies of filamentous Gram + bacilli. Id. = Bacillus firmus & $44.4 \%$ \\
Dry-looking colonies of nonfilamentous Gram + bacilli. Id. = Bacillus pumilus & $33.3 \%$ \\
Shiny white round colonies of Gram + bacilli. Id. = Staphylococcus equorum & $16.6 \%$ \\
Reddish colonies of Gram + bacilli. & $5.5 \%$ \\
Id. = Bacillus selenatarsenatis & \\
\hline
\end{tabular}

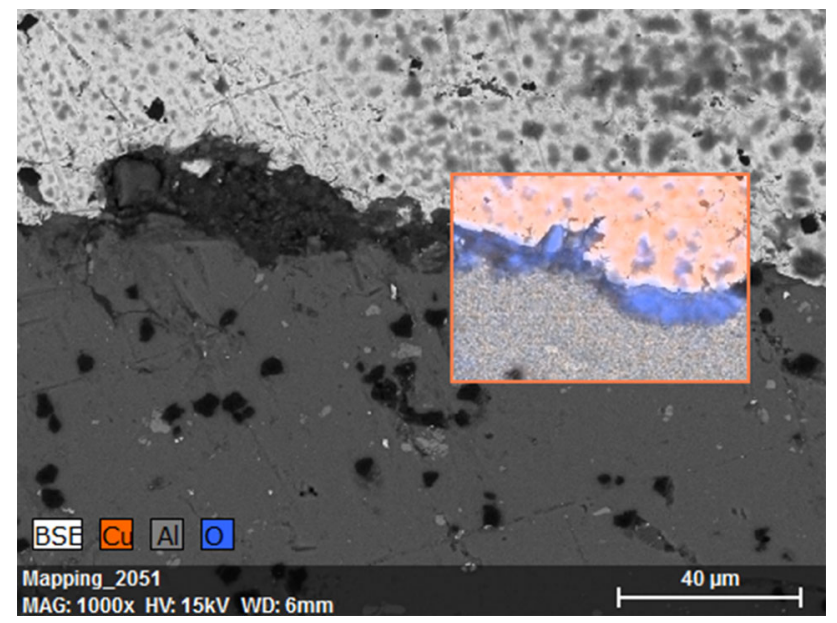

Figure 12 Cross section of CuNiZn alloy coating on aluminum substrate. EDS analysis shows formation of oxide scale on the interface.

The organic coatings applied in the industry are usually epoxy, epoxy/acrylic, or polyester enamels, with 25 to 40 volume percent solids and remaining are solvents, typical of which are esters, ketones, aliphatics, alcohols. The solvents released during polymerization and drying known as volatile organic compounds (VOCs). Furthermore, these solvents still continue to leach from the polymer coatings for a long time after deposition and are extremely harmful to indoor environments. Moreover, these coatings are not able to protect the wood from decay fungi and insects the way that preservatives do (Ref 61).

Thermal spray technology offers a unique way of applying a thin layer of copper or copper alloys on the surface of the wood. The metal coatings have no drying time and do not release any VOCs during service life.

Copper coatings have great adhesion to the wood and wood composite products, by creating mechanical interlocking bonds. Although the adhesion strength varies by wood species, if the wood surface is properly prepared (sanded by 80 grit sandpaper), the adhesion strength is usually higher than the mechanical strength of the wood. Since the adhesion of a thermal sprayed coating to wood is through mechanical interlocking, it is expected that the adhesion will be greatly influenced by wood's structure, which varies with wood species (Fig. 13) (Ref 62).

One would initially assume that depositing molten metal (at a temperature of $>1000^{\circ} \mathrm{C}$ ) on wood should burn and/or damage the surface of the wood, but analysis of the surface layer of wood right below copper coated showed no sign of burning or discoloration (Ref 62). This is due to the fact that with proper control of the process parameters, even though the molten metal droplets are at a high temperature, because of their small size, they carry little thermal energy, and thus, they are not able to cause damage to the wood.

Nejad et al. (Ref 62) studied the protective properties of copper coating on wood. They exposed $\mathrm{Cu}$-coated mahogany, oak, maple, pine, and MDF samples to four major mold species, including Aureobasidium Pullalans, Aspergillus Niger, Penicillium Thom, and Alternaria Tenuissima. After four months of exposure to mildew at $32^{\circ} \mathrm{C}$ and $95 \%$ relative humidity according to the AWPA E24-06 procedure, the coated surfaces were free of surface mold, while the uncoated side of samples showed massive mold growth.

The authors also tested the efficacy of $\mathrm{Cu}$ coating in protecting wood from decay fungi. Following AWAP E1006 standard, cubes of $\mathrm{Cu}$-coated and uncoated wood samples were exposed to Postia Placenta fungi for four months while stored in an incubator at $20^{\circ} \mathrm{C}$ and $65 \%$ relative humidity. The average weight loss of $\mathrm{Cu}$-coated samples was less than $4 \%$, while the average weight loss of uncoated samples was around 55\% (Fig. 14). Among 12 replicates of $\mathrm{Cu}$-coated samples, the minor weight loss observed in just a few of the samples was related to those that had some uncoated corners exposed, indicating that the proper application of $\mathrm{Cu}$ coating on wood can completely protect the wood from decay fungi.

Compared to preservative treatment that uses toxic chemicals (biocides) to protect the wood, coating the surface of the wood by thermal spraying of copper and its alloys creates a protective layer on the surface of the wood that these micro-organisms no longer recognize the wood to be a source of food. In addition to antimicrobial properties of $\mathrm{Cu}$ coating, and its ability to protect the wood from decay fungi and mildew, the ease of application of 
Figure 13 TWA copper coating adhesion (ASTM D4541) to mahogany (a), MDF (b), and adhesion values for different wood substrates (c).
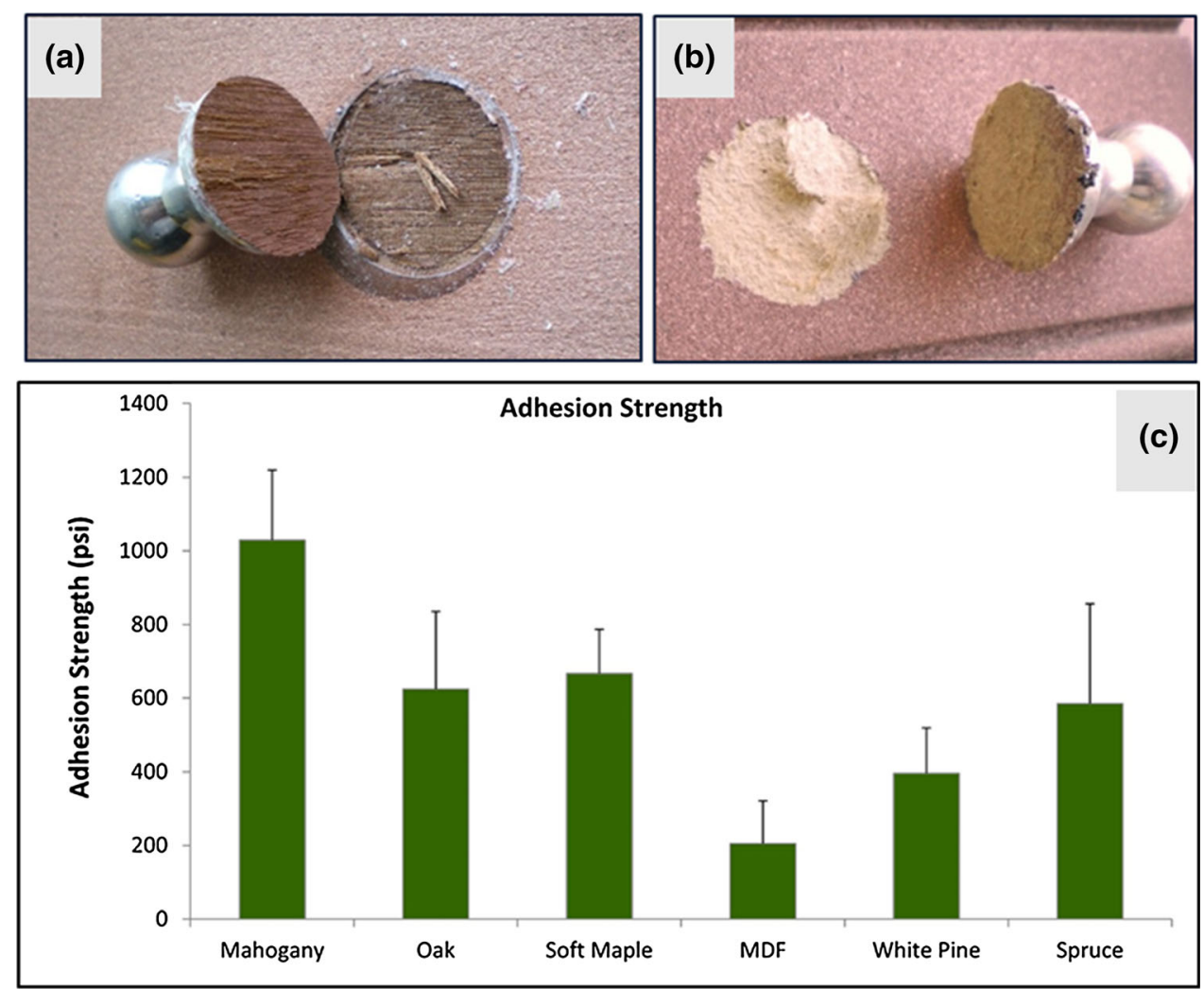

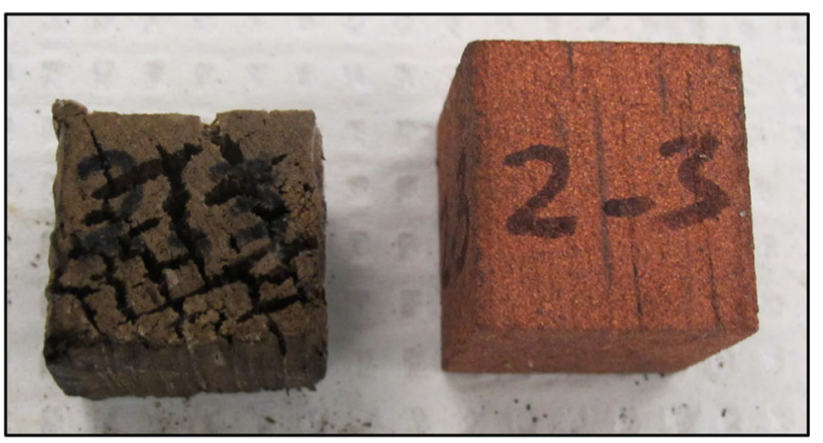

Figure 14 Bare wood (left) and Cu-coated (right) samples after 12 weeks of decay test [47]

thermal spray coating on wood, low energy requirement, no need to condition the wood after treatment for a week, or deal with environmental issues regarding the leaching of the preservative chemicals to the surrounding environment, all will prove why thermal spray coating is a great way to protect the wood, especially for interior applications.

\section{Conclusions}

Thermal sprayed coatings of copper alloys exhibited higher antibacterial properties compared to the conventionally manufactured sheets due to the unique nature of the microstructure. Copper-based alloys and deposited coatings' biocidal effectiveness are directly related to the copper content in the alloys.

CuNiZn alloy coatings were tested for several months in real-life hospital conditions at two institutions, Mount Sinai Hospital (Toronto, Canada) and Instituto de Medicina Tropical Alexander von Humboldt, Universidad Peruana Cayetano Heredia (Lima, Peru). The results show that the coatings provide long-lasting, durable, and low maintenance surfaces with strong antibacterial properties. An extensive study of the effect of copper coatings deposited on the arms of chairs in the Toronto General Hospital's waiting room showed a remarkable $68 \%$ in the average CFU count over a period of approximately six months. A thorough selection of coating and substrate compositions for future applications must consider their corrosion properties and the possible action of different cleaning and disinfection fluids to be used on them. Attention to peculiar environmental strains that may show increased resistance to copper is warranted. The desired beneficial effect of these antibacterial surfaces in reducing nosocomial and community infections needs to be investigated.

It was concluded that the surface roughness ( $\mathrm{Ra}$ ) for the range from as-sprayed $(6-10 \mu \mathrm{m})$ to polished $(1.0-0.1 \mu \mathrm{m})$ does not affect coatings antibacterial efficiency.

A thorough investigation of wood products as substrates for copper-based coatings was carried out. In addition to the anti-bacterial properties, the results showed that (a) the 
adhesion of the coating was normally stronger than the mechanical cohesion of the wood; (b) the coating provides protection against fungi and mildew; and several other important benefits, including environmental benefits, were observed.

Finally, we found that the twin-wire-arc spray technique is a preferable and economical process for depositing copper and copper alloys coatings on heat-sensitive substrates.

Acknowledgments The authors are thankful to Dr. Allison McGeer (Mount Sinai Hospital, Toronto, Ontario, Canada) and Dr. Michael Gardam (Department of Infection Prevention and Control, University Health Network, Toronto, Ontario, Canada), Dr. Humberto Guerra and Dr. Jessica Ricaldi (Universidad Peruana Cayetano Heredia, Instituto de Medicina Tropical Alexander von Humboldt, Lima, Peru), for their help and discussions during field studies.

Funding Financial support of Grand Challenges Canada, Natural Sciences and Engineering Research Council of Canada, and Ontario Centres of Excellence is gratefully acknowledged

\section{Appendix: Testing Protocol}

Gram-negative Escherichia coli (E. coli) or gram-positive Staphylococcus epidermidis bacteria were selected as representative of the two-broad category of bacteria, which are based on the composition of their cell wall and their differential retention of crystal violet during Gram staining. Single colonies of E. coli and S. epidermidis were cultured in Luria Broth at $37^{\circ} \mathrm{C}$ in an orbital shaker at $225 \mathrm{rpm}$ until $\log$ phase. The bactericidal activity of three types of coupons $\left(2 \mathrm{~cm}^{2}\right)$ was compared: stainless steel, brass sheet metal (EDS; $87 \%$ copper, $13 \%$ zinc), and phosphor bronze (EDS; $91.7 \%$ copper, $7.5 \%$ tin) thermally sprayed onto stainless steel. All copper-coated coupons were washed with $70 \%$ ethanol, rinsed with deionized water, and airdried. Aliquots of bacteria were added to the coupons and incubated at room temperature for various periods and then washed with $10 \mathrm{ml}$ phosphate-buffered saline (PBS). Aliquots of the suspensions were plated on Luria-Bertani agar plates and incubated at $37^{\circ} \mathrm{C}$ overnight to determine survival rates. Stainless steel coupons were used as controls. Viability was also assessed with a LIVE/DEAD BacLight viability kit (Invitrogen, Burlington, Ontario, Canada) containing SYTO9 and propidium iodine, which stains live bacteria that have intact plasma membranes fluorescent green and dead bacteria which have compromised plasma membranes florescent red, respectively. Bacterial fluorescence was visualized using fluorescence with Zeiss SteREO Discovery, V20. Bacterial counts were performed by counting individual fluorescent spots within three random fields of view per sample at 120X magnification. Scanning electron microscopy (SEM) analysis revealed that a fluorescent spot $9.5 \mu \mathrm{m}^{2}$ was representative of one bacterium, making it feasible to count individual cells. Dividing propidium red fluorescence by SYTO9 green fluorescence staining of individual bacteria quantified lethality.

\section{References}

1. D. Pittetab, B. Allegranzi, J. Storrb, S. Bagheri-Nejad, G. Dziekan, A. Leotsakosb and L. Donaldsonb, Infection Control as a Major World Health Organization Priority for Developing Countries, J. Hospital Infect., 2008, 68(4), p 285-292.

2. H.T. Michels and C.A. Michels, Can Copper Help Fight COVID19? Advanced Materials \& Processes-Digital First, ASM International Subscription, Cleveland, 2020.

3. G. Grass, C. Rensing and M. Solioz, Metallic Copper as an Antimicrobial SUrface, Appl. Environ. Microbiol., 2011, 77(5), p 1541-1547.

4. H.H.A. Dollwet and J.R.J. Sorenson, Historic Uses of Copper Compounds in Medicine, Trace Elem. Med., 1985, 2, p 80-87.

5. S.L. Warnes, E.N. Summergill and C.W. Keevil, Inactivation of Murine Norovirus on a Range of Copper Alloy Surfaces is Accompanied by Loss of Capsid Integrity, Appl. Environ. Microbiol., 2015, 81, p 1085-1091.

6. G. Leite and M. Padoveze, Copper as an Antimicrobial Agent in Healthcare: An Integrative Literature Review, J. Infect. Control., 2012, 1(2), p 33-36.

7. H. Michels, C. Michels, Copper Alloys-The New "Old" Weapon to Fight Against the Infectious Disease. Current Trends Microbiol. Vol 10, (2016)

8. S. Rai, B.E. Hirsch, H.H. Attaway, R. Nadan, S. Fairey, J. Hardy, G. Miller, D. Armellina, W.R. Moran, P. Sharpe, A. Estelle, J.H. Michel, H.T. Michels and M.G. Schmidt, Evaluation of the Antimicrobial Properties of Copper Surfaces in an Outpatient Infectious Disease Practice, Soc. Healthcare Epidemiol. Am., 2012, 33, p 200-201.

9. M. Samanovic, C. Ding, D.J. Thiele and K.H. Darwin, Copper in Microbial Pathogenesis: Meddling with the Metal, Cell Host Microbe, 2012, 11(2), p P106-115. https://doi.org/10.1016/j. chom.2012.01.009

10. D.J. Hassett and M.S. Cohen, Bacterial Adaptation to Oxidative Stress: Implications for Pathogenesis and Interaction with Phagocytic Cells, FASEB J., 1989, 3(14), p 2574-2582. https:// doi.org/10.1096/fasebj.3.14.2556311

11. K. Barnham, C. Masters and A. Bush, Neurodegenerative Diseases and Oxidative Stress, Nat. Rev. Drug. Discov., 2004, 3, p 205-214. https://doi.org/10.1038/nrd1330

12. J.B. Cross, R.P. Currier, D.J. Torraco, L.A. Vanderberg, G.L. Wagner and P.D. Gladen, Killing of Bacillus Spores by Aqueous Dissolved Oxygen, Ascorbic Acid, and Copper Ions, Appl. Environ. Microbiol., 2003, 69(4), p 2245-2252. https://doi.org/10. 1128/AEM.69.4.2245-2252.2003

13. L. Weaver, H.T. Michels and C.W. Keevil, Survival of Clostridium Difficile on Copper and Steel: Futuristic Options For Hospital Hygiene, J. Hospital Infect., 2008, 68(2), p P145-151. https://doi.org/10.1016/j.jhin.2007.11.011

14. S.L. Warnes and C.W. Keevil, Inactivation of Norovirus on Dry Copper Alloy Surfaces, PLoS ONE, 2013, 8(9), p e75017. https:// doi.org/10.1371/journal.pone.0075017

15. S. Mathews, M. Hans, F. Mücklich, M. Solioz, Contact Killing of Bacteria on Copper Is Suppressed if Bacterial-Metal Contact Is 
Prevented and Is Induced on Iron by Copper Ions. Appl. Environ. Microbiol. Vol 79, No. 8, (2013)

16. S.C. Espirito, N. Taudte, D.H. Nies and G. Grass, Contribution of Copper Ion Resistance to Survival of Escherichia Coli on Metallic Copper Surfaces, Appl. Environ. Microbiol., 2008, 74, p 977-986.

17. G. Grass, C. Rensing and M. Solioz, Metallic Copper as an Antimicrobial Surface, Appl. Environ. Microbiol., 2011, 77, p 1541-1547.

18. A.A. Cortes and J.M. Zuñiga, The Use of Copper to Help Prevent Transmission of SARS-Coronavirus and Influenza Viruses A General Review, Diagnostic Microbiol. Infectious Dis., 2020, 98(4), p 115176. https://doi.org/10.1016/j.diagmicrobio.2020. 115176

19. N. van Doremalen, T. Bushmaker, D.H. Morris et al., Aerosol and Surface Stability of SARS-CoV-2 as Compared with SARS-CoV1, $N$ Engl J Med, 2020, 382, p 1564-1567. https://doi.org/10. 1056/NEJMc2004973

20. S.L. Warnes, Z.R. Little and C.W. Keevil, Human Coronavirus 229E Remains Infectious on Common Touch Surface Materials, DOI: mBio, 2015, 6(6), p 01697-01715.

21. G. Hedin, J. Rynbäck, B. Loré, Reduction of Bacterial Surface Contamination in the Hospital Environment by Application of a New Product with Persistent Effect. J. Hospital Infect. Vol 75, Issue 2, (2010)

22. H.H. Attaway, S. Fairey, L.L. Steed, C.D. Salgado, H.T. Michels and M.G. Schmidt, Intrinsic Bacterial Burden Associated with Intensive Care Unit Hospital Beds: Effects of Disinfection on Population Recovery and Mitigation of Potential Infection Risk, Am. J. Infect. Control, 2012, 40(10), p 907-912. https://doi.org/ 10.1016/j.ajic.2011.11.019

23. A.L. Casey, D. Adams, T.J. Karpanen, P.A. Lambert, B.D. Cookson, P. Nightingale and T.S. Elliott, Role of Copper in Reducing Hospital Environment Contamination, J. Hosp. Infect., 2010, 74(1), p 72-77. https://doi.org/10.1016/j.jhin.2009.08.018

24. D. Hamilton, A. Foster, L. Ballantyne, P. Kingsmore, D. Bedwell, T.J. Hall and V.A. Gant, Performance of Ultramicrofibre Cleaning Technology with or Without Addition of a Novel CopperBased Biocide, J. Hosp. Infect., 2010, 74(1), p 62-71. https://doi. org/10.1016/j.jhin.2009.08.006

25. N.L. Havill, B.A. Moore and J.M. Boyce, Comparison of the Microbiological Efficacy Of Hydrogen Peroxide Vapor and Ultraviolet Light Processes for Room Decontamination, Infect. Control Hosp. Epidemiol., 2012, 33(5), p 507-512. https://doi. org/10.1086/665326

26. O. Sharifahmadian, H. Salimijazi, M. Fathi, J. Mostaghimi and L. Pershin, Study of the Antibacterial Behavior of Wire Arc Sprayed Copper Coatings, J. Therm. Spray Technol., 2013, 22, p 371-379.

27. P.L. Fauchais, J.V. Heberlein and M. Boulos, Thermal Spray Fundamentals: From Powder to Part, Springer, Berlin, 2014.

28. R. Zajchowski, H.B. Crapo, Evaluation of Three Dual-Wire Electric Arc-Sprayed Coatings: Industrial Note. J. Thermal Spray Technol. Vol 5, (1996)

29. E.R. Sampson, Economics of Arc Spray vs. Plasma for Aircraft Components, Thermal Spray Coatings: Research, Design and Applications. C.C. Berndt, T.E. Bernecki Ed., ASM International, Cleveland, 1993, p 257-262

30. J. Konig, M. Lahres and O. Methner, Quality Designed Twin Wire Arc Spraying of Aluminum Bores, JTST, 2015, 24(1-2), p 63.

31. P.S. Grant, S.R. Duncan, A. Roche, C.F. Johnson, Scientific, Technological, and Economic Aspects of Rapid Tooling by Electric Arc Spray Forming. JTST, Vol. 15, No. 4, (2006)

32. A. Carducci, M. Verani, R. Lombardi, B. Casini and G. Privitera, Environmental Survey to Assess Viral Contamination of Air and
Surfaces in Hospital Settings, J. Hosp. Infect., 2011, 77(3), p 242247. https://doi.org/10.1016/j.jhin.2010.10.010

33. A. Ferroni, A. Werkhauser-Bertrand, M. Le Bourgeois, R. Beauvais, S. Vrielynck, C. Durand and I. Sermet-Gaudelus, Bacterial Contamination in the Environment of Hospitalised Children with Cystic Fibrosis, J. Cyst. Fibros., 2008, 7(6), p $477-$ 482.

34. L. Lodola, G. Bernardini, A. Riva and P. Marraccini, Evaluation and Quantification of Biologic Risk in the Hospital Setting with ATP Determination on Work Surfaces, Giornale Italiano di Medicina del Lavoro Ed Ergonomia, 2000, 22(1), p 7-13.

35. J.D. Sexton, B.D. Tanner, S.L. Maxwell and C.P. Gerba, Reduction in the Microbial Load on High-Touch Surfaces in Hospital Rooms by Treatment with a Portable Saturated Steam Vapor Disinfection System, Am. J. Infect. Control, 2011, 39(8), p 655-662.

36. E. A. Hooker, S. D. Allen, L. D. Gray, Terminal Cleaning of Hospital Bed Mattresses and Bedecks Does Not Eliminate Bacterial Contamination. American Journal of Infection Control. Conference: 38th Annual Educational Conference and International Meeting of the Association for Professionals in Infection Control and Epidemiology, Inc., APIC, 39(5), E23-E24, (2011)

37. A. Frabetti, A. Vandini, P. Balboni, F. Triolo and S. Mazzacane, Experimental Evaluation of the Efficacy of Sanitation Procedures in Operating Rooms, Am. J. Infect. Control, 2009, 37(8), p 658664.

38. J.H. Michel, H.T. Michels, W.R. Moran, A.A. Estelle, K.E. Sexton, M.G. Schmidt, American Foundry Society, Antimicrobial Copper: Clinical Performance Against Bacteria That Cause Infections and Impact of Their Use on Hospital Patients, Vol 120 American Foundry Society Inc, Schaumburg, 2012.

39. L. Taylor, P. Phillips and R. Hastings, Reduction of Bacterial Contamination in a Healthcare Environment by Silver Antimicrobial Technology, J. Infect. Prevent., 2009, 10(1), p 6-12.

40. O. Sharifahmadian, H.R. Salimijazi, M.H. Fathi, J. Mostaghimi and L. Pershin, Relationship Between Surface Properties and Antibacterial Behavior of Wire Arc Spray Copper Coatings, $J$. Surface Coat. Technol., 2013, 233, p 74-79.

41. R. Shafaghi, J. Mostaghimi, L. Pershin and M. Ringuette, Sporicidal Efficacy of Thermal-Sprayed Copper Alloy Coating, Can. J. Microbiol., 2017, 63, p 384-391.

42. G. Kear, B.D. Barker, K. Stokes and F.C. Walsh, Electrochemical Corrosion Behaviour of 90-10 Cu-Ni Alloy in Chloride-Based Electrolytes, J. Appl. Electrochem., 2004, 34, p 659-669.

43. N. George, M. Mahon, and A. McDonald, Bactericidal Performance of Flame-Sprayed Nanostructured Titania-Copper Composite Coatings. J. Thermal Spray Technol. Vol 19, No. 5, (2010)

44. N. Sanpo, S.A. Ang, P. Cheang and K.A. Khor, Antibacterial Properties of Cold Sprayed Chitosan-Cu/Al Coating, J. Therm. Spray Technol., 2019, 18(4), p 600-608.

45. A. Wrona, K. Bilewska, M. Lis, M. Kamińska, T. Olszewski, P. Pajzderski, G. Więcław, M. Jaśkiewicz and W. Kamysz, Antimicrobial Properties of Protective Coatings Produced by Plasma Spraying Technique, Surface Coat. Technol., 2017, 318, p 332-340.

46. D. Tegero-Martin et al., Beyond traditional thermal spray coatings: A review on thermal sprayed functional and smart coatings, J. Thermal Spray Technol., 2019, 28, p 598-644.

47. K.J. Brobbey, J. Haapanen, M. Tuominen, J.I. Mäkelä, M. Gunell, E. Eerola, J. Saarinen and M. Toivakka, High-Speed Production of Antibacterial Fabrics Using Liquid Flame Spray, Textile Res. J., 2020, 90(5-6), p 503-511.

48. E. Ivanova, V. Truong, J. Wang, Ch. Berndt et al., Impact of Nanoscale Roughness of Titanium Thin Film Surfaces on Bacterial Retention, Langmuir, 2010, 26(3), p 1973-1982. 
49. L.G. Harris, S. Tosatti, M. Wieland, M. Textor and R.G. Richards, Staphylococcus Aureus Adhesion to Titanium Oxide Surfaces Coated with Non-Functionalized and Peptide-Functionalized Poly (1-lysine)-Grafted-Poly(ethyleneglycol) Copolymers, Biomaterials, 2004, 25, p 4135-4148.

50. R. Bos, H.C. Van Der Mei and H.J. Busscher, Physico-Chemistry of Initial Microbial Adhesive Interactions-Its Mechanisms and Methods for Study, FEMS Microbiol. Rev., 1999, 23, p 179-229.

51. L.R. Hilbert, D. Bagge-Ravn, J. Kold and L. Gram, Influence of Surface Roughness of Stainless Steel on Microbial Adhesion and Corrosion Resistance, Int. Biodeteriorat. Biodegrad., 2003, 52, p 175-185.

52. T.R. Scheuerman, A.K. Camper and M.A. Hamilton, Effects of Substratum Topography on Bacterial aDhesion, J. Colloid Interface Sci., 1998, 208, p 23-33.

53. R.D. Boyd, J. Verran, M. Jones and M. Bhakoo, Use of the Atomic Force Microscope to Determine the Effect of Substratum Surface Topography on Bacterial Adhesion, Langmuir, 2002, 18, p 2343-2346.

54. C.J. Barnes, T.H.C. Childs, B. Henson and C.H. Southee, Surface Finish and Touch - A Case Study in a New Human Factors Tribology, Wear, 2004, 257(7-8), p 740-750.

55. FPS, Wood Handbook-Wood as an Engineering Material, US Department of Agriculture Forest Service, Forest Product Lab. Madison, WI, USA. Gen. Tech. Rep. FPLGTR-113, (1999).
56. T. Williamson, APA Engineered Wood Handbook, McGraw-Hill, New York, 2001.

57. M. H. Freeman, C. R. Mcintyre, Micronized Copper Wood Preservatives: Strong Indications of the Reservoir Effect. Int. Res. Gr. Wood Preserv., p. IRG/WP 13-30609, (2013)

58. C. Civardi, M. Schubert, A. Fey, P. Wick and F.W.M.R. Schwarze, Micronized Copper Wood Preservatives: Efficacy of Ion, Nano, and Bulk Copper Against the Brown Rot Fungus Rhodonia Placenta, PLoS ONE, 2015, 10(11), p e0142578.

59. S. Lebow and D. Foster, Environmental Concentrations of Copper, Chromium, and Arsenic Released from a Chromated-Copper-Arsenate- (CCA-C-) Treated Wetland Boardwalk, For. Prod. $J ., 2005, \mathbf{5 5}(2)$, p 62-70.

60. M. Nejad, T. Ung, P. Cooper, Effect of Coatings on ACQ Preservative Component Distribution and Solubility After Natural Weathering Exposure. Wood Sci. Technol. Vol. 46, No. 6, (2012)

61. P. Evans et al., Weathering and Surface Protection of Wood, Handb. Environ. Degrad. Mater. Pp 277-297, (2005)

62. M. Nejad, R. Shafaghi, L. Pershin, J. Mostaghimi and P. Cooper, Thermal Spray Coating: A New Way of Protecting Wood, BioResources, 2017, 12(1), p 143-156.

Publisher's Note Springer Nature remains neutral with regard to jurisdictional claims in published maps and institutional affiliations. 